\title{
Design and synthesis of small molecular 2-aminobenzoxazoles as potential antifungal agents against phytopathogenic fungi
}

\author{
Lingling Fan ${ }^{1} \cdot$ Zhongfu Luo $^{1} \cdot$ Changfei Yang $^{1} \cdot$ Bing Guo $^{1} \cdot$ Jing Miao ${ }^{1} \cdot$ Yang Chen $^{2} \cdot$ Lei Tang $^{1} \cdot$ Yong Li $^{1}$
}

Received: 20 January 2021 / Accepted: 19 March 2021 / Published online: 3 April 2021

(c) The Author(s), under exclusive licence to Springer Nature Switzerland AG 2021

\begin{abstract}
In order to discover novel antifungal agents, three series of simple 2-aminobenzoxazole derivatives were designed, synthesized and evaluated for their antifungal activities against eight phytopathogenic fungi. The in vitro antifungal results showed that most of the target compounds exhibited excellent and broad-spectrum antifungal activities to all the tested fungi. Particularly, the six compounds $\mathbf{3 a}, \mathbf{3 b}, \mathbf{3 c}, \mathbf{3 e}, \mathbf{3} \mathbf{m}$ and $\mathbf{3 v}$ displayed the most potent antifungal activity, with $\mathrm{EC}_{50}$ value of $1.48-16.6 \mu \mathrm{g} / \mathrm{mL}$, which were much superior to the positive control hymexazol. The in vivo study further confirmed that compounds 3a, 3c, 3e and 3m displayed good preventative effect against Botrytis cinerea at the concentration of $100 \mu \mathrm{g} /$ $\mathrm{mL}$. The structure-activity relationships research provides significant reference for the further structural optimization of 2-aminobenzoxazole as potential fungicides.
\end{abstract}

\section{Graphic abstract}

Forty-four 2-aminobenzoxazole derivatives were designed and synthesized as agricultural antifungal agents, the in vitro and in vivo antifungal experiments showed that compounds $\mathbf{3 a}, \mathbf{3 b}, \mathbf{3 c}, \mathbf{3 e}, \mathbf{3} \mathbf{m}$ and $\mathbf{3 v}$ exhibited excellent and broad-spectrum antifungal activities compare with the commercial fungicide hymexazol.
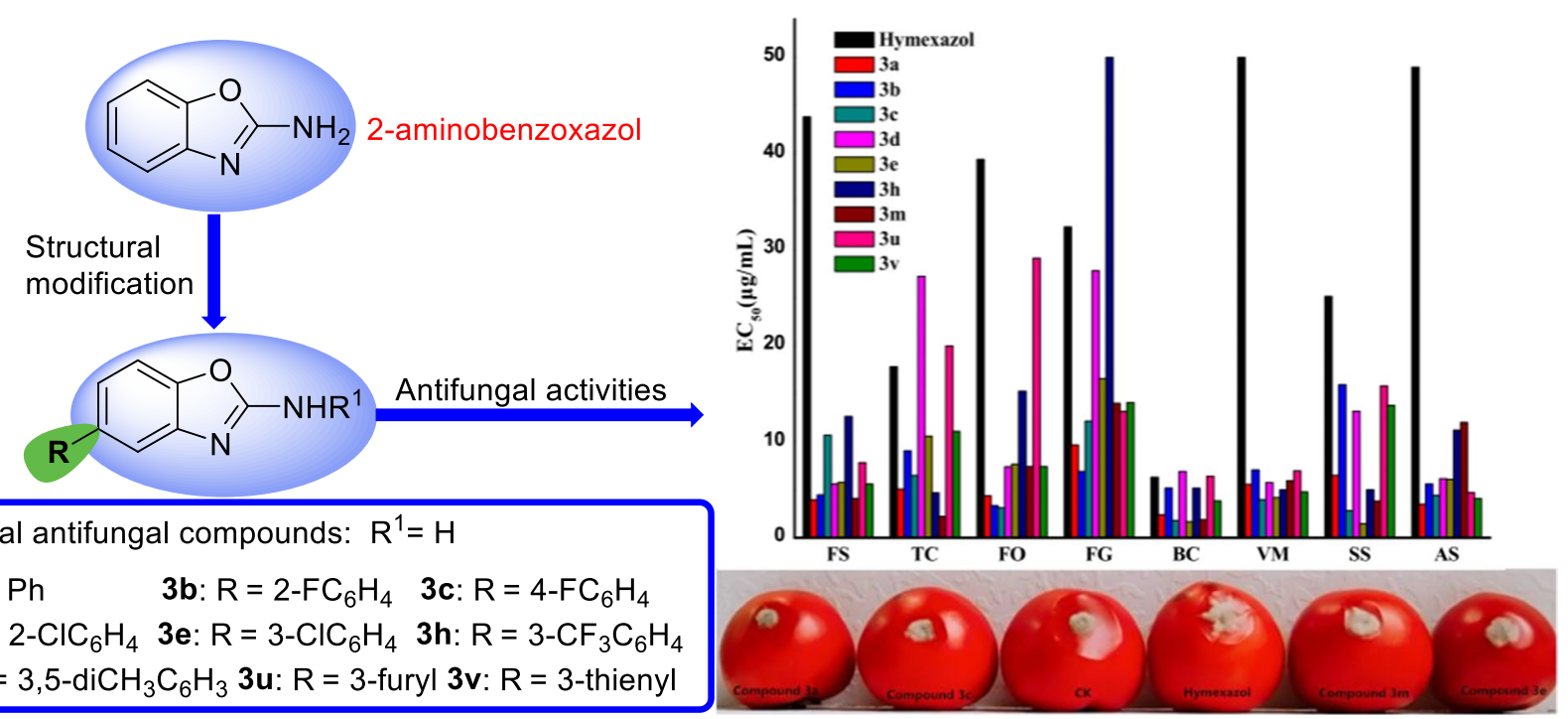

Keywords 2-Aminobenzoxazole derivatives $\cdot$ Pathogenic fungi $\cdot$ Antifungal activity $\cdot$ Structure-activity relationships

Lei Tang

tlei1974@hotmail.com

Yong Li

liyong19851016@126.com

Extended author information available on the last page of the article 


\section{Introduction}

Phytopathogenic fungi can seriously interrupt the normal growth of crops, fruits and vegetables, which not only lead to serious economic losses of agriculture worldwide, but also some species can produce mycotoxins that are harmful to human and animal health. In the past decades, many fungicides that target different pathogens and diseases have been used to improve agricultural production and ensure food security, but some fungicides have been restricted due to toxic residues, disease resurgence and pathogen resistance [1]. Therefore, it is necessary to develop novel antifungal agents with low toxicity and high efficiency to control agricultural diseases.

Benzoxazole, an important class of heterocyclic scaffolds, exhibits broad biological activities in the fields of medicinal and agricultural, including antiproliferative [2], anticancer [3, 4], anti-HIV [5], antimicrobial [6-9], antiviral [10], herbicidal [11] and antifungal activity [12]. As shown in Fig. 1, some reported drugs containing benzoxazole skeleton were listed. For example, benoxaprofen and flunoxaprofen are non-steroidal anti-inflammatory drugs (NSAIDs), reportedly useful in the treatment of rheumatoid arthritis, myositis, synovitis and osteoarthritis $[13,14]$. Calcimycin, an antibiotic and divalent cation ionophore, is a structural unique benzoxazole polyether produced by Streptomyces chartreusis NRRL3882 [15]. Oxazosulfyl, a novel benzoxazole insecticide containing ethyl sulfonyl pyridine fragment, was developed by Sumitomo Chemical Co., Ltd. Thus, benzoxazole is a magical and useful chemical group, which is worthy of being studied further.
To the best of our knowledge, 2-aminobenzoxazole as an important intermediate for the synthesis of antitumor drugs has rarely reported the antifungal activity against plant pathogenic fungi. In continuation of our program aimed at the discovery and development of novel antifungal candidates [16-21], herein we design and synthesize three series of 2-aminobenzoxazole derivatives and evaluated their antifungal activities against eight phytopathogenic fungi.

\section{Results and discussion}

\section{Chemistry}

As shown in Scheme 1, firstly, 2-nitrophenols were reduced by $\mathrm{SnCl}_{2} \cdot 2 \mathrm{H}_{2} \mathrm{O}$ to afford 2 -aminophenol derivatives $(\mathbf{1 a}-\mathbf{c})$ [22], which were further cyclized with cyanogen bromide $(\mathrm{BrCN})$ in methanol to give the key intermediates 5-substituted 2-aminobenzoxazoles (2a-d). Then, C-5-alkyl-substituted 2-aminobenzoxazole derivatives (3a-y) were smoothly obtained by Suzuki cross-coupling reaction. Meanwhile, amides $(\mathbf{4 a}-\mathbf{j})$ and sulfonamides $(\mathbf{5} \mathbf{a}-\mathbf{i})$ derivatives were conveniently prepared by acylation reaction. The structures of all the target compounds were characterized by M. p., ${ }^{1} \mathrm{H}$ $\mathrm{NMR},{ }^{13} \mathrm{C}$ NMR and HRMS.

\section{Antifungal activity}

According to the mycelium linear growth rate method [19], all the target compounds (2a-d, 3a-y, $\mathbf{4 a}-\mathbf{j}$ and $\mathbf{5 a}-\mathbf{i})$ were screened in vitro for their antifungal activities at $50 \mu \mathrm{g} / \mathrm{mL}$ against eight phytopathogenic fungi [e.g., Fusarium sulphureum (FS), Thanatephorus cucumeris (TC), Fusarium

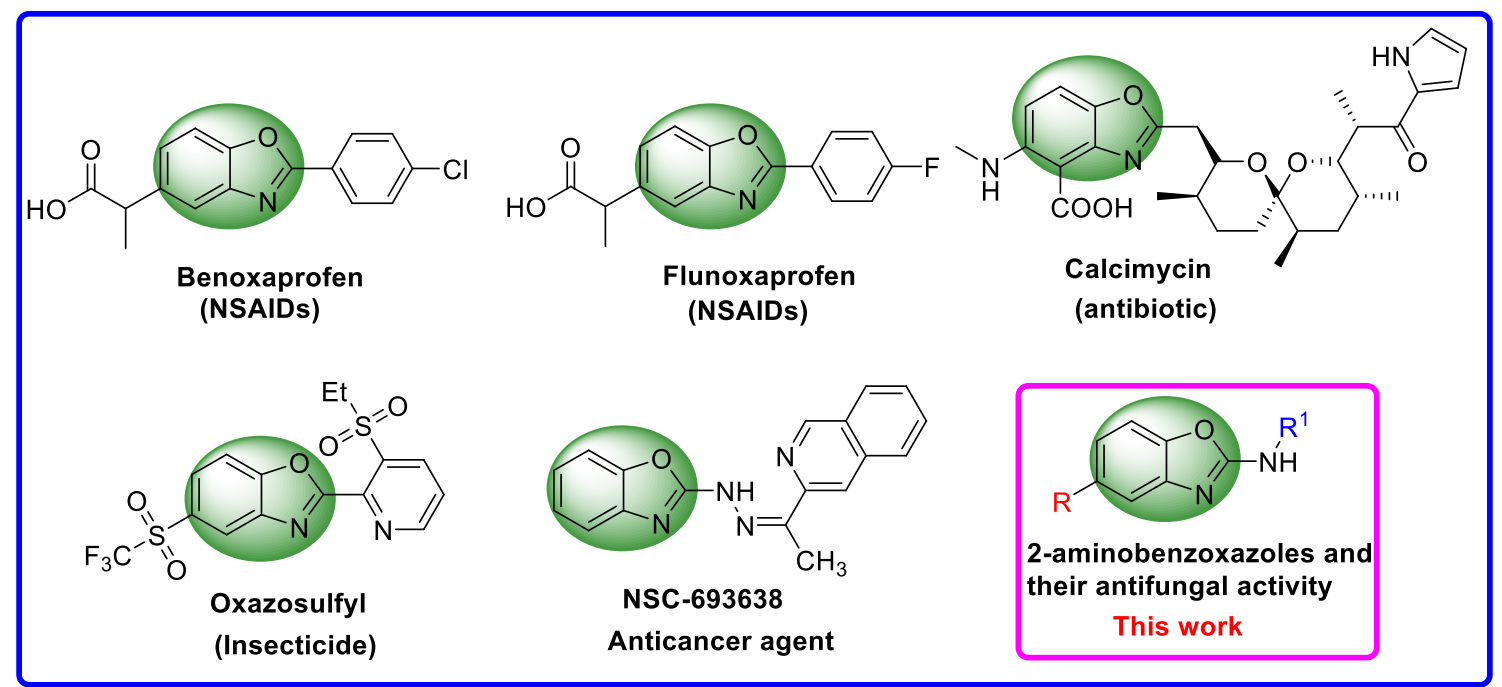

Fig. 1 Chemical structures of containing benzoxazole skeleton 


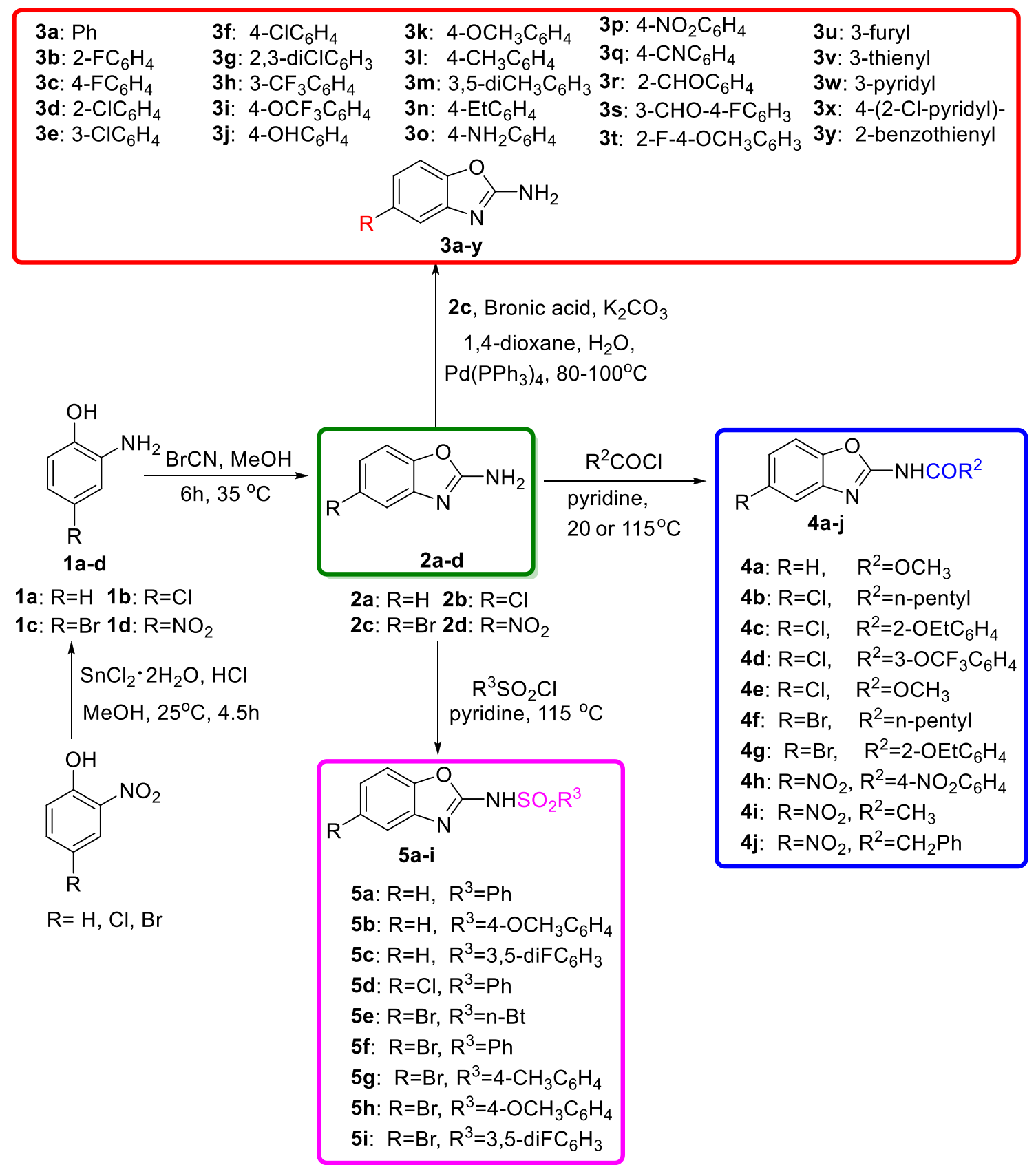

Scheme 1 General synthetic rout of target compounds

oxysporum (FO), Fusarium graminearum (FG), Botrytis cinerea (BC), Valsa mali (VM), Sclerotiua sclerotiorum (SS) and Alternaria solani (AS)]. Hymexazol, a commercial agricultural fungicide, was used as the positive control.

As depicted in Table 1, most of the target compounds displayed good-to-excellent inhibitory effects on the growth of the tested phytopathogenic fungi at $50 \mu \mathrm{g} / \mathrm{mL}$. Generally, these compounds can be divided into three groups according to the average inhibition rates. Compounds $\mathbf{3 a}-\mathbf{e}, \mathbf{3 h}$, $\mathbf{3 m}, \mathbf{3 u}$ and $\mathbf{3 v}$ showed the highest activity with average inhibition rates of $80.7-97.5 \%$, compounds $\mathbf{2 b}, \mathbf{2 c}, \mathbf{3 f}, \mathbf{3 i}, \mathbf{3 k}$, 3p, 3q, 3t, 3x, 4h and 5e exhibited moderate activity with average inhibition rates of $46.1-70.2 \%$, and the other compounds displayed weak activity against the tested fungi. For FS strain, it was worth mentioning that thirty compounds exhibited more pronounced antifungal activity ( $>52.2 \%)$ than the positive control hymexazol (50.4\%); particularly, the inhibition rates of compounds $\mathbf{3 a}, \mathbf{3 b}, \mathbf{3 d}, \mathbf{3 e}$ and $\mathbf{3 v}$ reached $100 \%$ at the concentration of $50 \mu \mathrm{g} / \mathrm{mL}$. For TC strain, seven compounds $\mathbf{3 a}, \mathbf{3 b}, \mathbf{3 c}, \mathbf{3 e}, \mathbf{3 h}, \mathbf{3 m}$ and $\mathbf{3 v}$ 


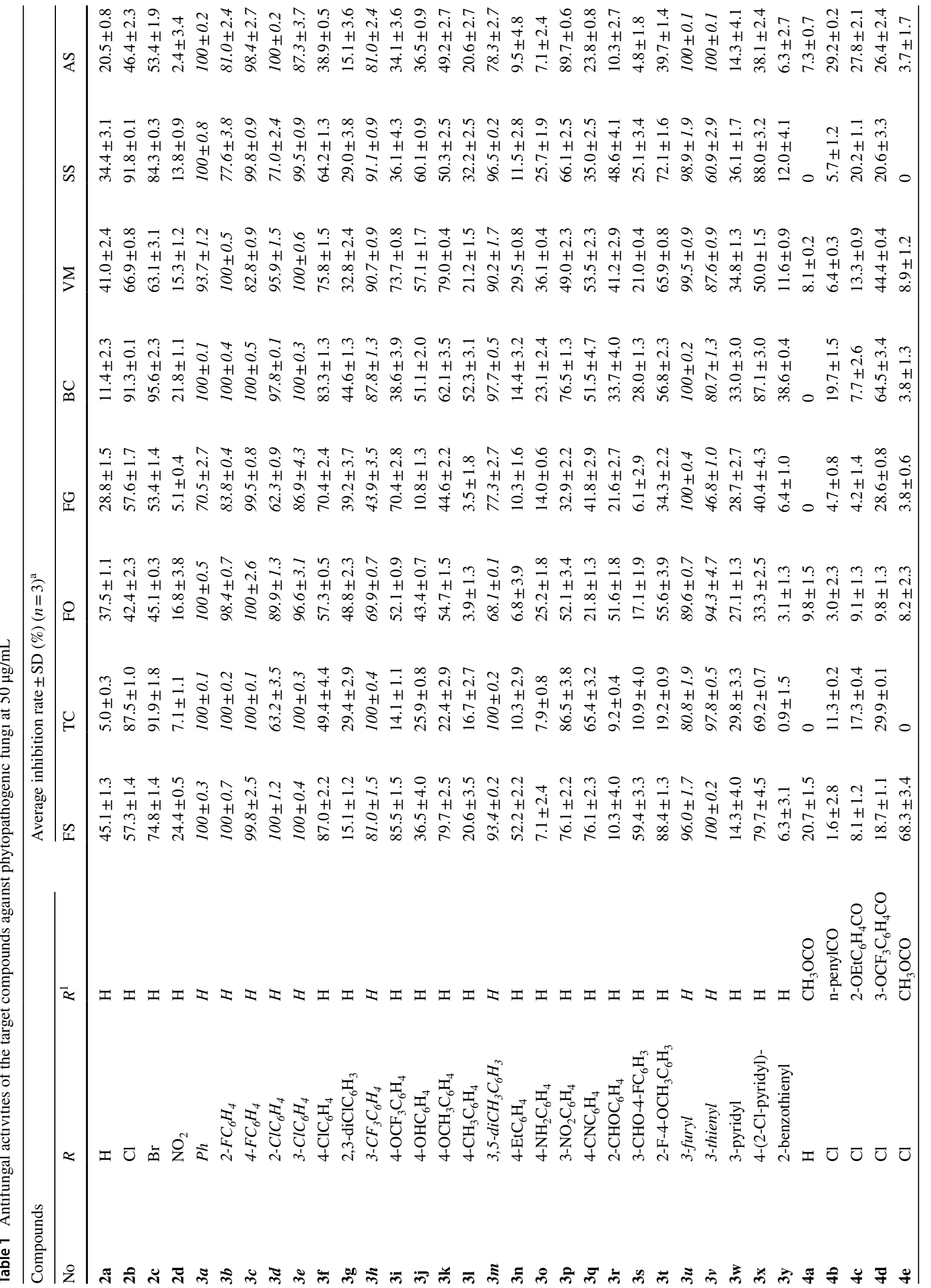




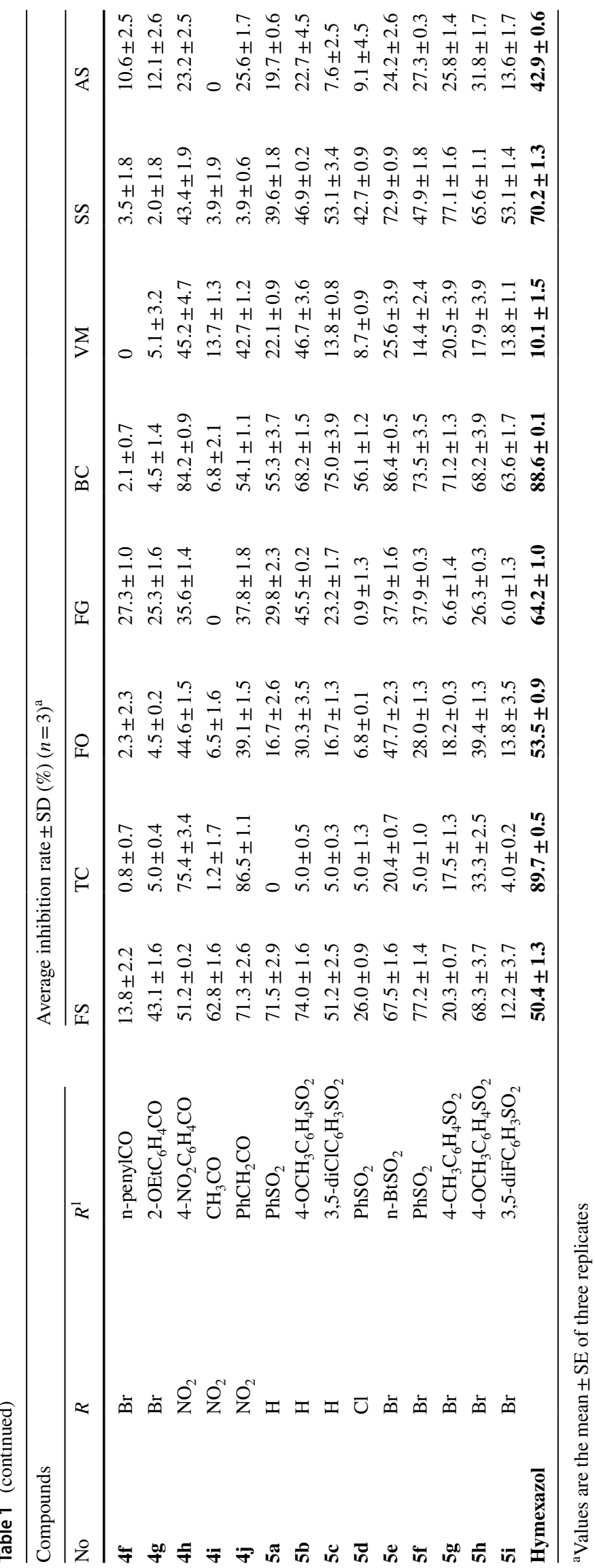


showed considerable antifungal activity with inhibition rates over $97.8 \%$, which were much better than that of hymexazol $(89.7 \%)$. Furthermore, compounds $\mathbf{3 a - 3 f}, \mathbf{3 m}$ and $\mathbf{3 v}$ were found to exhibit higher antifungal activity against $\mathrm{FO}$ and FG strains than hymexazol, and compounds $\mathbf{2 b}, \mathbf{2 c}, \mathbf{3 a}-\mathbf{3 e}$, $\mathbf{3 h}, \mathbf{3 m}$ and $\mathbf{3 u}$ possessed significant antifungal activity against BC, SS and AS (53.4-100\%) in comparison with hymexazol (42.9-88.6\%). To our delight, almost all the target compounds displayed better antifungal activity against VM than hymexazol (10.1\%). In general, compounds $\mathbf{3 a}, \mathbf{3 b}$, 3c, $\mathbf{3 e}$ and $\mathbf{3 m}$ presented more promising antifungal activity against a broad spectrum of phytopathogenic fungi than the commercial agricultural fungicide hymexazol.

Moreover, some interesting results of structure-activity relationships (SARs) were found as follows (Fig. 2): (1) Introduction of chlorine and bromine atoms is very beneficial to enhance the antifungal activity (2b and $\mathbf{2 c}$ vs. 2a and 2d). (2) Amino group is very essential for the antifungal activity, acylation and sulfonylation which can obviously decrease the activity against some tested fungi. (3) Compared with the intermediate compound 2c, selection of suitable aryl groups replacing bromine atom can significantly improve the antifungal effects, such as the inhibition rates of compounds $\mathbf{3 a}(\mathrm{Ph}), \mathbf{3 b}\left(2-\mathrm{FC}_{6} \mathrm{H}_{4}\right)$, 3c $\left(4-\mathrm{FC}_{6} \mathrm{H}_{4}\right), \mathbf{3 d}\left(2-\mathrm{ClC}_{6} \mathrm{H}_{4}\right), \mathbf{3 e}\left(3-\mathrm{ClC}_{6} \mathrm{H}_{4}\right), \mathbf{3 m}$ $\left(3,5-\mathrm{diCH}_{3} \mathrm{C}_{6} \mathrm{H}_{3}\right), 3 \mathbf{u}$ (3-furyl) and $\mathbf{3 v}$ (3-thienyl) against most of strains were over $90 \%$. (4) It is noteworthy that introduction of electron-withdrawing groups (such as $\mathrm{F}$, $\mathrm{Cl}, \mathrm{CF}_{3}, \mathrm{NO}_{2}$ and $\mathrm{CN}$ ) at the 5-position on phenyl ring of compound $\mathbf{3 a}$ could result in more potent compounds than electron-donating groups (such as $\mathrm{OH}, \mathrm{CH}_{3}, \mathrm{Et}, \mathrm{NH}_{2}$ ) excepted for compounds $\mathbf{3 g}$ and $\mathbf{3 m}(\mathbf{3 b}-\mathbf{3 f}, \mathbf{3 h}, \mathbf{3 p}$ and 3q vs. 3j, 3l, 3n and 3o). (5) The number and position of chlorine atom also have some influence on the antifungal activity. For instance, mono-chloro compounds (3d, 3e and 3f) exhibited much better antifungal activity than the corresponding bis-chloro compound $(\mathbf{3 g})$, and the effect of chlorine atom position on antifungal activity was meta(3e) $>$ ortho-(3d) $>$ para-(3f). (6) The target compounds bearing furan $(3 \mathbf{u})$ and thiophene $(3 \mathbf{v})$ ring at the 5-position of compound $\mathbf{2 a}$ displayed better inhibition effects than those bearing a pyridine (3w), 2-chloropyridine (3x) and benzothiophene ring (3y). The aforementioned result demonstrates that the antifungal effect can be dramatically influenced by the substituents group on the $\mathrm{NH}_{2}$ and 5-position of 2-aminobenzoxazole.

To further evaluate the inhibitory of the most promising synthesized compounds, the median effective concentrations $\left(\mathrm{EC}_{50}\right)$ values of compounds $\mathbf{3 a}-\mathbf{e}, \mathbf{3 h}, \mathbf{3 m}, \mathbf{3} \mathbf{u}$ and 3v against eight phytopathogenic fungi were tested. As shown in Table 2 , it was noticed that the nine compounds exhibited impressive antifungal effects against FS, FO, VM, SS and AS, which were better than that of hymexazol. For example, compounds $\mathbf{3 a}, \mathbf{3 b}$ and $\mathbf{3 m}$ exhibited the best anti-FS effects in vitro, with the $\mathrm{EC}_{50}$ values as low as $3.96 \mu \mathrm{g} / \mathrm{mL}, 4.47 \mu \mathrm{g} / \mathrm{mL}$ and $4.10 \mu \mathrm{g} / \mathrm{mL}$, respectively; compounds 3a-e, 3m and 3v exhibited 5.1-12.6 folds more potent activities than hymexazol against FO strain; five compounds $\mathbf{3 a}, \mathbf{3 c}, \mathbf{3 e}, \mathbf{3 h}$ and $\mathbf{3 m}$ exhibited remarkable antifungal activity against $\mathrm{SS}$ strains in vitro, with the corresponding $\mathrm{EC}_{50}$ values of $6.50 \mu \mathrm{g} / \mathrm{mL}, 2.82 \mu \mathrm{g} / \mathrm{mL}$, $1.48 \mu \mathrm{g} / \mathrm{mL}, 5.00 \mu \mathrm{g} / \mathrm{mL}$ and $3.82 \mu \mathrm{g} / \mathrm{mL}$, much superior to hymexazol $(25.12 \mu \mathrm{g} / \mathrm{mL})$. Furthermore, all the target compounds (except 3d and 3u) possessed higher antifungal effects than hymexazol against $\mathrm{TC}$ and $\mathrm{BC}$ strains. Regarding FG strains, compounds $\mathbf{3 a}\left(\mathrm{EC}_{50}=9.68 \mu \mathrm{g} / \mathrm{mL}\right)$ and $\mathbf{3 b}\left(\mathrm{EC}_{50}=6.91 \mu \mathrm{g} / \mathrm{mL}\right)$ are identified with excellent antifungal competence, compounds $\mathbf{3 m}, \mathbf{3 u}, \mathbf{3 v}, \mathbf{3 c}$ and $\mathbf{3 e}$ displayed moderate activity $\left(\mathrm{EC}_{50}=12.16-16.60 \mu \mathrm{g} / \mathrm{mL}\right)$, and compound 3d with the $\mathrm{EC}_{50}$ value of $27.8 \mu \mathrm{g} / \mathrm{mL}$, which was comparable with that of hymexazol $(32.36 \mu \mathrm{g} /$ $\mathrm{mL}$ ). This result suggested that the tested fungal displayed high susceptibility to the nine compounds. Meanwhile, the effects of compound $\mathbf{3 d}$ on the growth of FS and FO strains

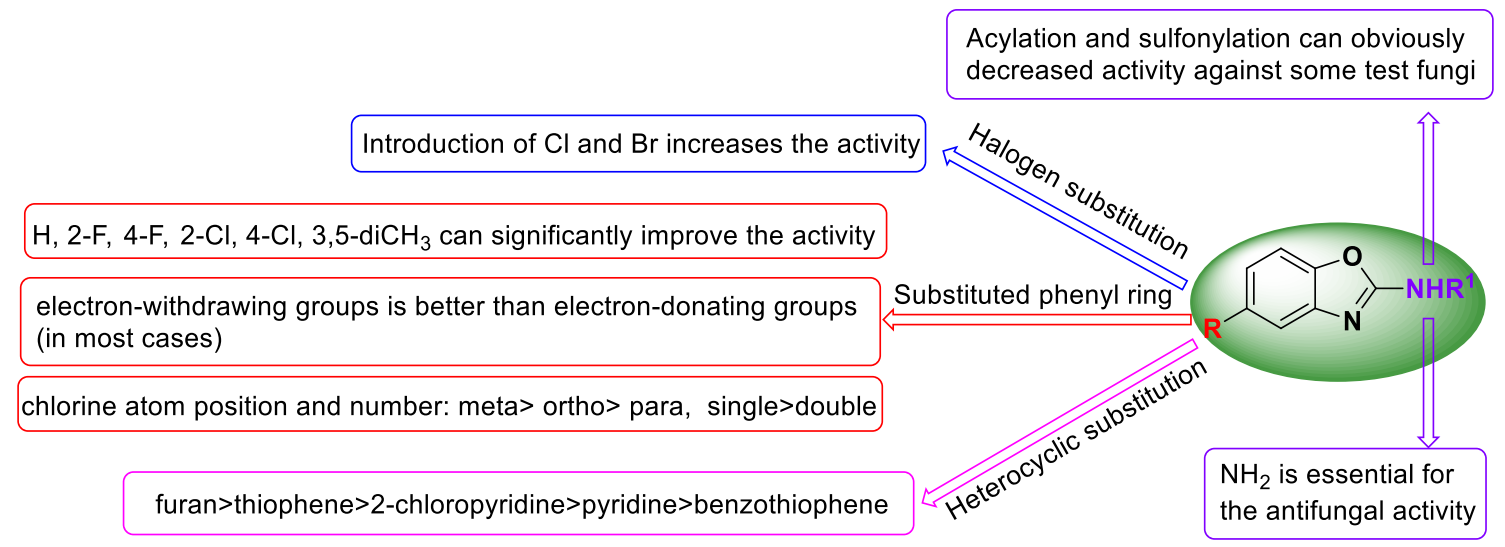

Fig. 2 Structure-activity relationship of the target compounds 
Table $2 \mathrm{EC}_{50}$ values of some selected compounds against eight phytopathogenic fungi

\begin{tabular}{|c|c|c|c|c|c|c|c|c|}
\hline \multirow[t]{2}{*}{ Compounds } & \multicolumn{8}{|c|}{$\mathrm{EC}_{50} \pm \mathrm{SD}$ values $(\mu \mathrm{g} / \mathrm{mL})^{\mathrm{a}}$} \\
\hline & FS & TC & FO & FG & $\mathrm{BC}$ & VM & SS & AS \\
\hline $3 \mathbf{a}$ & $3.96 \pm 0.2$ & $5.08 \pm 0.2$ & $4.36 \pm 0.4$ & $9.68 \pm 1.1$ & $2.40 \pm 0.5$ & $5.56 \pm 0.2$ & $6.50 \pm 0.7$ & $3.50 \pm 0.2$ \\
\hline $3 b$ & $4.47 \pm 0.1$ & $9.07 \pm 1.2$ & $3.35 \pm 0.5$ & $6.91 \pm 0.9$ & $5.18 \pm 0.8$ & $7.07 \pm 0.3$ & $15.95 \pm 0.5$ & $5.60 \pm 0.1$ \\
\hline $3 c$ & $10.69 \pm 0.3$ & $6.49 \pm 0.5$ & $3.13 \pm 0.2$ & $12.16 \pm 2.1$ & $1.81 \pm 0.2$ & $3.97 \pm 0.1$ & $2.82 \pm 0.2$ & $4.43 \pm 0.3$ \\
\hline 3d & $5.60 \pm 0.1$ & $27.23 \pm 0.4$ & $7.40 \pm 0.8$ & $27.8 \pm 1.9$ & $6.91 \pm 0.3$ & $5.75 \pm 1.1$ & $13.20 \pm 1.1$ & $6.15 \pm 0.6$ \\
\hline $3 \mathbf{e}$ & $5.77 \pm 0.2$ & $10.60 \pm 0.7$ & $7.67 \pm 0.2$ & $16.60 \pm 1.4$ & $1.69 \pm 0.8$ & $4.19 \pm 0.2$ & $1.48 \pm 0.3$ & $6.10 \pm 0.9$ \\
\hline $3 \mathbf{h}$ & $12.65 \pm 0.4$ & $4.69 \pm 0.5$ & $15.27 \pm 1.0$ & $>50$ & $5.17 \pm 0.7$ & $4.99 \pm 0.1$ & $5.00 \pm 1.0$ & $11.22 \pm 1.2$ \\
\hline $3 m$ & $4.10 \pm 0.3$ & $2.23 \pm 0.3$ & $7.41 \pm 0.1$ & $14.02 \pm 0.2$ & $1.89 \pm 1.4$ & $5.95 \pm 0.2$ & $3.82 \pm 0.7$ & $12.02 \pm 1.3$ \\
\hline $3 \mathbf{u}$ & $7.83 \pm 0.1$ & $19.95 \pm 1.4$ & $28.10 \pm 0.7$ & $13.18 \pm 2.1$ & $6.42 \pm 0.5$ & $6.98 \pm 0.2$ & $15.82 \pm 0.6$ & $4.71 \pm 0.6$ \\
\hline $3 v$ & $5.60 \pm 0.1$ & $11.10 \pm 1.1$ & $7.41 \pm 0.3$ & $14.09 \pm 0.4$ & $3.85 \pm 0.1$ & $4.78 \pm 1.2$ & $13.81 \pm 0.5$ & $4.10 \pm 0.2$ \\
\hline Hymexazol & $43.8 \pm 0.6$ & $17.78 \pm 2.1$ & $39.40 \pm 1.1$ & $32.36 \pm 2.0$ & $6.30 \pm 0.2$ & $>\mathbf{5 0}$ & $25.12 \pm 0.5$ & $48.98 \pm 2.1$ \\
\hline
\end{tabular}

${ }^{\mathrm{a}} 50 \%$ Effective concentration: concentration of compound that inhibits the fungi growth

at different concentrations are shown in Fig. 3. It's obviously that the antifungal efficiency significantly depended on the drug concentrations.

The morphological changing of Fusarium solani (FS) and Alternaria solani (AS) was then viewed under the light microscope. From Fig. 4, it can be seen that the FS control group mycelium had an eel shape, smooth surface, uniform size and much-branched, but the compound 3a treatment group mycelium appeared invagination, shriveling and fewbranched (FS-CK vs. FS-3a). Meanwhile, the AS mycelium of treatment with compound $\mathbf{3 a}$ could produce more less oval-shaped spores than that of control group (AS-CK vs. AS-3a). This phenomenon indicated that these compounds might exert antifungal effect by significantly inhibiting the growth and differentiation of fungal.

Finally, the in vivo antifungal effects of the promising compounds were conducted against Botrytis cinerea on tomato at $100 \mu \mathrm{g} / \mathrm{mL}$. As shown in Fig. 5, compounds 3a, 3c, 3e and 3m exhibited much better preventative effect than hymexazol $(23.1 \%)$, with the corresponding preventative rates of $46.7 \%, 48.3 \%, 55.1 \%$ and $53.3 \%$. The results verified that 2-aminobenzoxazole derivatives could be used as a lead compounds for the discovery of novel agrichemicals.

\section{Molecular docking studies}

Studies in the literature have reported that lipid transfer protein Sec14p (Saccharomyces cerevisiae) might be a potential target of inducing fungicidal activity by benzoxazole derivatives [12]. In an effort to elucidate the hypothesis that our compounds acted on sec $14 \mathrm{p}$, molecular docking of compounds $\mathbf{3 a}, \mathbf{3 b}, \mathbf{3 d}, \mathbf{3 h}, \mathbf{3 m}$ and $\mathbf{3 u}$ into the homology model according to the binding site of benzoxazoles on reported lipid binding pocket of Sec14p was performed, respectively. As shown in Fig. 6, the six-test compounds shared very similar binding modes with the literature reported. Benzoxazole ring was oriented pi-pi stacked interaction with Tyr 151 and pi-alkyl interaction with Arg208. The substituted phenyl ring made pi-pi stacked, pi-donor hydrogen bond and pi-alkyl interactions with Phe212 and Thr175 and Met209, respectively. This result suggested that the tested compounds were compatible with the active site of sec $14 \mathrm{p}$.
Fig. 3 Effects of compound 3d on the growth of FS and FO at different concentrations (CK: blank control group)
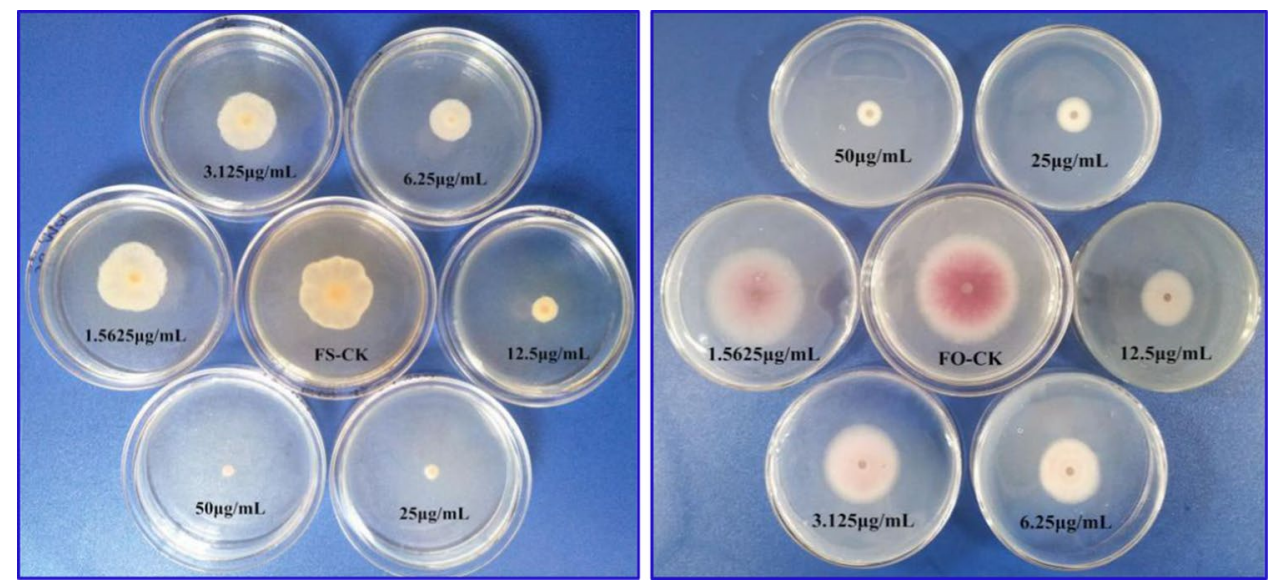
Fig. 4 The effects of compound 3a on the growth of FS and AS at $25 \mu \mathrm{g} / \mathrm{mL}$ (FS-CK and AS-CK represented the normal mycelium morphology of FS and AS, and FS-3a and AS-3a represented the mycelium morphology of FS and AS after treatment with compound $\mathbf{3 a}$ )
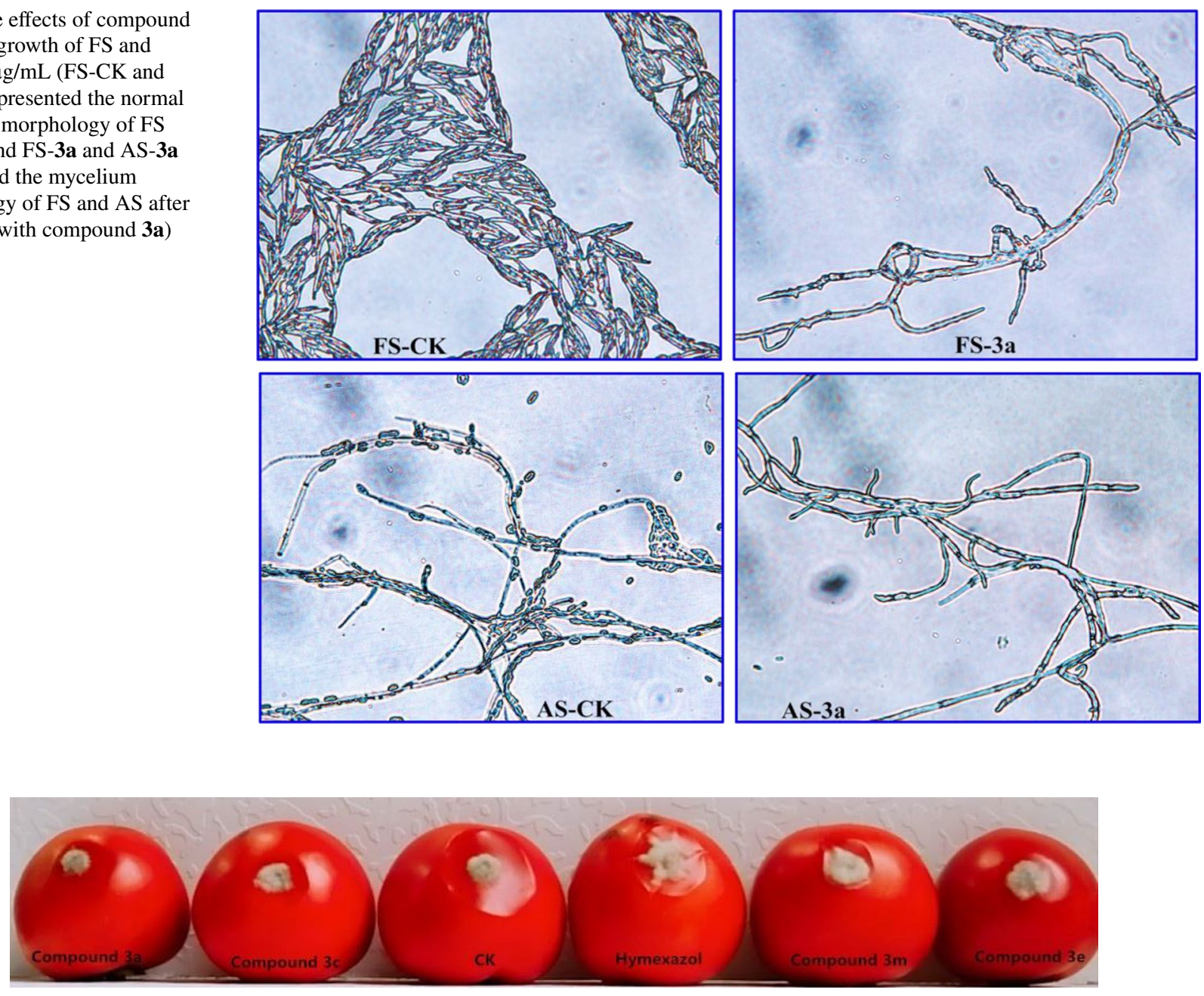

\begin{tabular}{ccccccc}
\hline Compounds $(100 \mu \mathrm{g} / \mathrm{mL})$ & Hymexazol & 3a & 3c & 3e & 3m & CK \\
\hline Preventative Rate (\%) & $23.1 \pm 2.3$ & $46.7 \pm 1.1$ & $48.3 \pm 0.1$ & $55.1 \pm 1.3$ & $53.3 \pm 0.5$ & -
\end{tabular}

Fig. 5 In vivo antifungal activity of compounds against Botrytis cinerea

\section{Conclusion}

In summary, three series of simple 2-aminobenzoxazole derivatives were synthesized and firstly evaluated for their antifungal activities. To our delight, most of the target compounds demonstrated moderate-to-excellent antifungal activities in vitro; particularly, compounds $\mathbf{3 a}, \mathbf{3 b}, \mathbf{3 c}, \mathbf{3 e}$, $\mathbf{3} \mathbf{m}$ and $3 \mathbf{v}$ presented more promising and comprehensive antifungal capacity against the corresponding phytopathogenic fungi than the commercialized fungicide hymexazol, with the $\mathrm{EC}_{50}$ values of $2.40-9.68 \mu \mathrm{g} / \mathrm{mL}, 3.35-15.95 \mu \mathrm{g} /$ $\mathrm{mL}, 1.81-10.69 \mu \mathrm{g} / \mathrm{mL}, 1.48-16.6 \mu \mathrm{g} / \mathrm{mL}, 1.89-14.02 \mu \mathrm{g} /$ $\mathrm{mL}$ and 3.85-14.09 $\mu \mathrm{g} / \mathrm{mL}$, respectively. Moreover, the in vivo experiments against Botrytis cinerea on tomato bioassay also demonstrated that compounds $\mathbf{3 a}, \mathbf{3 c}, \mathbf{3 e}$ and $\mathbf{3} \mathbf{m}$ had much better preventative effect than that of hymexazol. Thus, these compounds can be used as potential agricultural fungicides to protect many crops, vegetable and fruit. In addition, the SARs demonstrated that introduction of appropriate substituents on the 5-position of 2-aminobenzoxazole would lead to more potent derivatives. This study will lay a significant foundation for further preparation and application of 2-aminobenzoxazole derivatives as potential small molecular agrochemicals. 

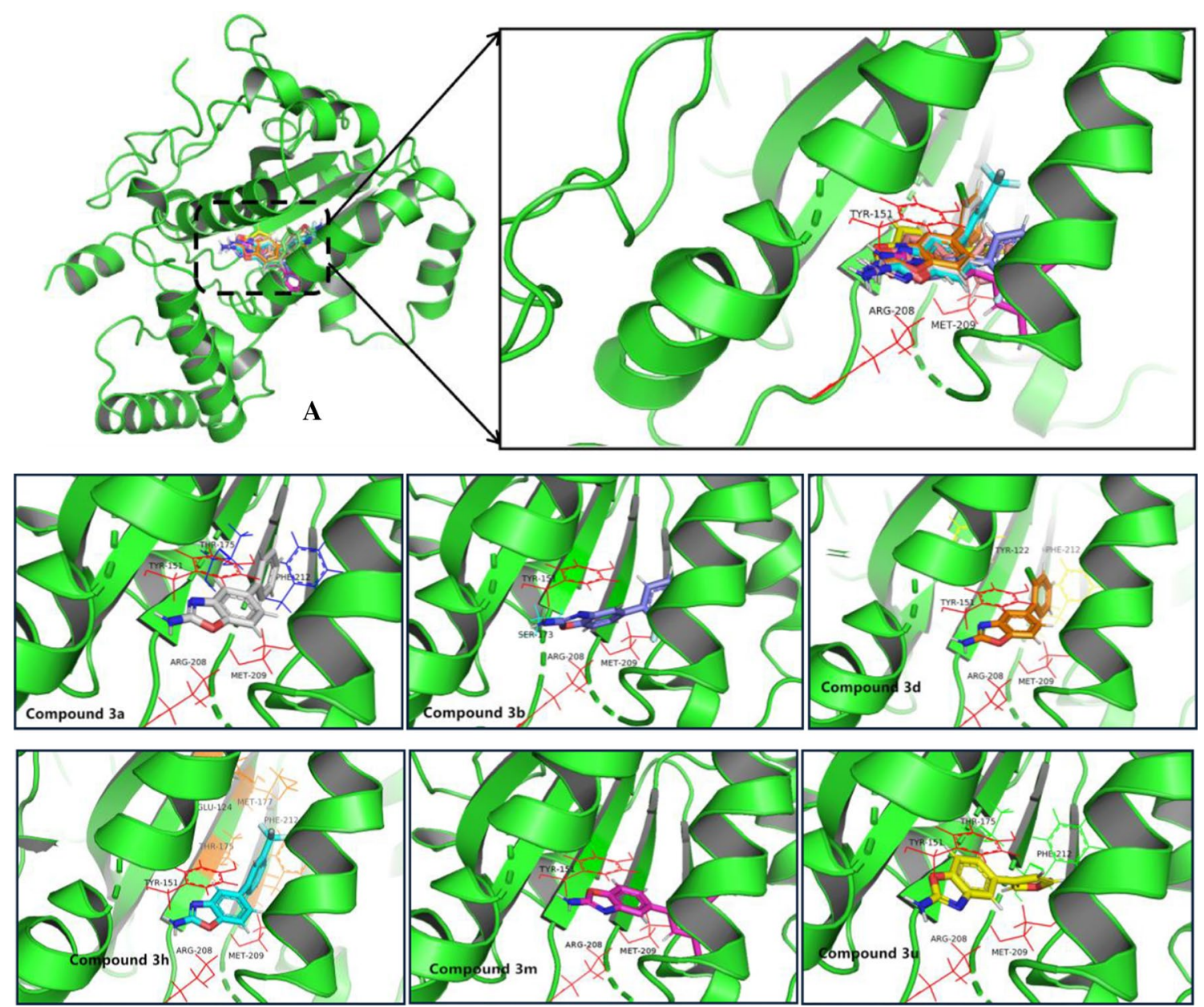

Fig. 6 The binding models of the test compounds into the lipid binding pocket of Sec $14 \mathrm{p}$ from S. cerevisiae. a Overlay of the six test compounds into the active site of Sec14p: 3a (gray), 3b (blue), 3d (orange), $\mathbf{3 h}$ (light blue), 3m (peach) and $\mathbf{3 u}$ (yellow)

\section{Experimental}

All reagents and solvents were of reagent grade or purified according to standard methods before use. Thinlayer chromatography (TLC) and preparative thin-layer chromatography (PTLC) were used with silica gel 60 GF254 (Qingdao Haiyang Chemical Co., Ltd., China). Melting points were determined by XY-4 melting point meter (Beijing Taike Instrument Co., Ltd., China). Proton nuclear magnetic resonance spectra $\left({ }^{1} \mathrm{H}\right.$ NMR) and carbon-13 nuclear magnetic resonance spectra $\left({ }^{13} \mathrm{C}\right.$ NMR) were recorded on Bruker Avance NEO 600/400 MHz and $150 / 100 \mathrm{MHz}$ instruments, respectively, using TMS as the internal standard and $\mathrm{CDCl}_{3}$ or DMSO- $d_{6}$ as the solvent. High-resolution mass spectra (HR-MS) were carried out with APEX II Bruker 4.7TAS instrument.

\section{Synthesis of compounds 1a-c [22]}

A solution of Stannous chloride dihydrate $\left(\mathrm{SnCl}_{2} \cdot 2 \mathrm{H}_{2} \mathrm{O}\right.$, $40 \mathrm{~g}, 177.3 \mathrm{mmol})$ and $\mathrm{HCl}(80 \mathrm{~mL})$ in methanol $(150 \mathrm{~mL})$ was cooled to $0{ }^{\circ} \mathrm{C}$, and 2-nitrophenol derivatives (36.7 $\mathrm{mmoL}$ ) was added. The mixture was stirred for $4.5 \mathrm{~h}$ at room temperature. Afterwards, the solution was diluted with ethyl acetate $(30 \mathrm{~mL})$ and neutralized with $\mathrm{NaHCO}_{3}$ solution (to $\mathrm{PH}=7$ ). Subsequently, the solution was filtered to remove the white solid precipitated, then the organic phase was separated, and the water phase was extracted with ethyl acetate $(50 \mathrm{~mL} \times 3)$. Finally, the resulting organic phases was washed with brine, dried over anhydrous $\mathrm{Na}_{2} \mathrm{SO}_{4}$ and evaporated under reduced pressure. The crude material was then purified by silica gel column chromatography to give the compounds 1a-c in $85-90 \%$ yield as a white or fawn solid. 
1a: ESI-MS $(\mathrm{m} / \mathrm{z})$ : $110.05(\mathrm{M}+\mathrm{H})^{+}$; 1b: ESI-MS (m/z): 144.02 $(\mathrm{M}+\mathrm{H})^{+}$; 1c: ESI-MS (m/z): $187.94(\mathrm{M}+\mathrm{H})^{+}$.

\section{Synthesis of compounds $2 a-d$}

Cyanogen bromide (35.9 mmol) was added to a solution of 2-aminophenol derivatives $(26.5 \mathrm{mmol})$ in $25 \mathrm{~mL}$ methanol, and the mixture was reacted for $6 \mathrm{~h}$ at the $35^{\circ} \mathrm{C}$. Subsequently, the organic solvent was removed and the resulting residue was diluted with cold water, and the $\mathrm{pH}$ was adjusted to 8-9 with aqueous $\mathrm{NaHCO}_{3}$ and then extracted with EtOAc $(3 \times 50 \mathrm{~mL})$. Finally, the resulting organic phases were washed with brine $(30 \mathrm{~mL})$, dried over anhydrous $\mathrm{Na}_{2} \mathrm{SO}_{4}$ and evaporated under reduced pressure. The crude material was then purified by silica gel column chromatography to give the compound $\mathbf{2 a - d}$.

\section{2-Aminobenzoxazole (2a)}

Yield: $88.0 \%$; brown solid; m.p. $121-122{ }^{\circ} \mathrm{C} ;{ }^{1} \mathrm{H}$ NMR $\left(400 \mathrm{MHz}, \mathrm{DMSO}-d_{6}\right) \delta: 9.56(\mathrm{~s}, 2 \mathrm{H}), 7.36(\mathrm{~d}, 2 \mathrm{H}$, $J=8.0 \mathrm{~Hz}), 7.16(\mathrm{t}, 2 \mathrm{H}, J=8.0 \mathrm{~Hz})$. ESI-MS $(\mathrm{m} / \mathrm{z}): 135.05$ $(\mathrm{M}+\mathrm{H})^{+}$.

\section{2-Amino-5-chlorobenzoxazole (2b)}

Yield: $85.2 \%$; white solid; m.p. $159-161{ }^{\circ} \mathrm{C}$; ${ }^{1} \mathrm{H}$ NMR $\left(400 \mathrm{MHz}, \mathrm{DMSO}-d_{6}\right) \delta: 7.61(\mathrm{~s}, 2 \mathrm{H}), 7.34(\mathrm{~d}, 1 \mathrm{H}$, $J=8.4 \mathrm{~Hz}), 7.23(\mathrm{~d}, 1 \mathrm{H}, J=2.2 \mathrm{~Hz}), 6.97(\mathrm{dd}, 1 \mathrm{H}, J=8.4$, $2.2 \mathrm{~Hz})$. ESI-MS (m/z): $169.01(\mathrm{M}+\mathrm{H})^{+}$.

\section{2-Amino-5-bromobenzoxazole (2c)}

Yield: 75.3\%; brown solid; m.p. $175-177{ }^{\circ} \mathrm{C}$; ${ }^{1} \mathrm{H}$ NMR $\left(400 \mathrm{MHz}, \mathrm{DMSO}-d_{6}\right) \delta: 7.59(\mathrm{~s}, 1 \mathrm{H}), 7.34(\mathrm{~s}, 1 \mathrm{H}), 7.29(\mathrm{~d}$, $1 \mathrm{H}, J=7.6 \mathrm{~Hz}), 7.10(\mathrm{~d}, 1 \mathrm{H}, J=7.6 \mathrm{~Hz})$; ESI-MS $(\mathrm{m} / \mathrm{z})$ : $212.90(\mathrm{M}+\mathrm{H})^{+}$.

\section{5-Nitrobenao[d]oxazol-2-amine (2d)}

Yield: 89.3\%; yellow solid; m.p. $275-277{ }^{\circ} \mathrm{C} ;{ }^{1} \mathrm{H}$ NMR $\left(400 \mathrm{MHz}, \mathrm{DMSO}-d_{6}\right) \delta: 8.02(\mathrm{~s}, 2 \mathrm{H}), 7.92(\mathrm{~m}, 2 \mathrm{H}), 7.53$ $(\mathrm{d}, 1 \mathrm{H}, J=8.4 \mathrm{~Hz})$; ESI-MS (m/z): $180.02(\mathrm{M}+\mathrm{H})^{+}$.

\section{The general procedures for synthesis of compounds 3a-y}

In a $25-\mathrm{mL}$ round-bottom flask containing dioxane $/ \mathrm{H}_{2} \mathrm{O}$ $(V: V=5: 1)(3 \mathrm{~mL}), \mathrm{K}_{2} \mathrm{CO}_{3}(110 \mathrm{mg}, 0.752 \mathrm{mmol}), 2$-amino5-bromobenzoxazole (2c, $83 \mathrm{mg}, 0.376 \mathrm{mmol})$, substituted boronic acid $(0.41 \mathrm{mmol})$ and $\mathrm{Pd}\left(\mathrm{PPh}_{3}\right)_{4}(14 \mathrm{mg}, 0.01 \mathrm{mmol})$ were added and reacted at $80{ }^{\circ} \mathrm{C}$ under $\mathrm{N}_{2}$. When the reaction was complete (TLC control), the organic solvent was removed. The crude material was then purified by silica gel column chromatography to give desired products $\mathbf{3 a}-\mathbf{y}$. The data of compounds $\mathbf{3 a}-\mathbf{y}$ can be found in the Supporting information.

\section{The general procedures for synthesis of compounds $4 a-j$ and $5 a-i$}

In a $25-\mathrm{mL}$ round-bottom flask containing pyridine $(1 \mathrm{~mL})$, 2-aminobenzoxazole derivatives $(0.5 \mathrm{mmol})$ and substituted acyl chloride/sulfonyl chloride $(0.55 \mathrm{mmol})$ were added and reacted at $20^{\circ} \mathrm{C}$ (4a and $\mathbf{4 e}$ ) or $115^{\circ} \mathrm{C}$ under $\mathrm{N}_{2}$. The reaction progress was checked by TLC analysis. When the reaction was complete, the mixture was poured into the water and adjusted to the $\mathrm{pH}=3-4$ by $6 \mathrm{~N} \mathrm{HCl}$. Then, the mixture was extracted with EtOAc $(3 \times 20 \mathrm{~mL})$, and the combined organic phase was dried over anhydrous sodium sulfate $\left(\mathrm{Na}_{2} \mathrm{SO}_{4}\right)$, concentrated in vacuo and purified by silica gel column chromatography to afford compounds $\mathbf{4 a}-\mathbf{j}$ and $\mathbf{5 a}-\mathbf{i}$. The data of compounds $\mathbf{4} \mathbf{a}-\mathbf{j}$ and $\mathbf{5 a}-\mathbf{i}$ can be found in the Supporting information.

\section{Antifungal assay}

Antifungal activities assay in vitro: three series of benzoxazole derivatives were screened in vitro for their antifungal activities against eight phytopathogenic fungi by the mycelial growth inhibitory rate method according to previously reported approaches [19]. Eight phytopathogenic fungi such as Fusarium sulphureum (FS), Thanatephorus cucumeris (TC), Fusarium oxysporum (FO), Fusarium graminearum (FG), Botrytis cinerea (BC), Valsa mali (VM), Alternaria alternata (AA) and Alternaria solani (AS) were used for the assays. Potato dextrose agar (PDA) medium was prepared in the flasks and sterilized. All target compounds were dissolved in acetone before mixing with PDA, and the concentration of test compounds in the medium was fixed at $50 \mu \mathrm{g} / \mathrm{mL}$. Subsequently, $50 \%$ effective concentration $\left(\mathrm{EC}_{50}\right)$ values of some selected compounds were further calculated. The medium was then poured into sterilized Petri dishes. All types of fungi were incubated in PDA at $28 \pm 1{ }^{\circ} \mathrm{C}$ for 5 days to get new mycelium for the antifungal assays, and a mycelia disk of approximately $4 \mathrm{~mm}$ diameter cut from culture medium was picked up with a sterilized inoculation needle and inoculated in the center of the PDA Petri dishes. The inoculated Petri dishes were incubated at $28 \pm 1{ }^{\circ} \mathrm{C}$ for 4 days. Acetone without any compounds mixed with PDA was served as a control, while hymexazol, a commercial agricultural fungicide, was used as positive controls. For each treatment, three replicates were conducted. The radial growths of the fungal colonies were measured, and the data were statistically analyzed. The inhibitory effects of 
the test compounds on these fungi in vitro were calculated by the formula: Inhibition rate $(\%)=(C-T) \times 100 /$ $(C-4 \mathrm{~mm})$, where $C$ represents the diameter of fungi growth on untreated PDA, and $T$ represents the diameter of fungi on treated PDA. Finally, the linear regressions of inhibition rates (\%) versus seven concentrations of some selected compounds and hymexazol were obtained, and the $\mathrm{EC}_{50}$ values were calculated. The therapeutic effect of the test compounds on $B$. cinerea in vivo was calculated by the formula: Therapeutic effect $(\%)=(C-T) \times 100 /$ $(C-4 \mathrm{~mm})$, where $C$ represents the diameter of $B$. cinerea growth on $\mathrm{CK}$, and $\mathrm{T}$ represents the diameter of $B$. cinerea on treated group [23]. Statistical analysis was processed by the SPSS 21.0 (SPSS Inc., Chicago, USA) software.

\section{Molecular docking studies}

The crystal structure the lipid transfer protein $\sec 14 \mathrm{p}$ from Saccharomyces cerevisiae was provided from the Brookhaven protein data bank (PDB 6F0E; http://www.rcsb. org/pdb). Docking studies were performed by using SYBYLX 2.0 software. Geometric and energy optimization of these compounds was conducted with Gasteiger-Huckel charges in the Tripos force field and an energy convergence gradient of $0.005 \mathrm{kcal} / \mathrm{mol}$ and a maximum of 10,000 iterations. The receptor-ligand interactions on 2D diagram was calculated by using Discovery Studio visualizer v21.1. The analysis of docking poses was carried out by molecular graphics system PYMOL v2.2.1 (DeLano Scientific LLC, USA).

\section{Supporting Information}

Spectral images of ${ }^{1} \mathrm{H}-\mathrm{NMR},{ }^{13} \mathrm{C}-\mathrm{NMR}$ and HRMS are provided in the Supporting Information Section.

Supplementary Information The online version contains supplementary material available at https://doi.org/10.1007/s11030-021-10213-7.

Acknowledgements This research was supported by the National Natural Science Foundation of China (No. 32060627), Guizhou Provincial Engineering Laboratory for Chemical Drug R\&D (No. [2016]5402), Guizhou Provincial Natural Science Foundation (Nos. [2019]1269 and [2020]1Y111), The Project of Postgraduate Scientific Research Fund of Guizhou (No. YJSCXJH[2019]077), National University Students Innovation and Entrepreneurship Training Program (Nos. 20195200120 and 202010660002) and National Natural Science Foundation of Guizhou Medical University (No. 19NSP075).

\section{Declarations}

Conflict of interest The authors declare that they have no conflict of interest.

\section{References}

1. Brauer VS, Rezende CP, Pessoni AM, Paula RGD, Rangappa KS, Nayaka SC, Gupta VK, Almeida F (2019) Antifungal agents in agriculture: friends and foes of public health. Biomolecules 9(10):521. https://doi.org/10.3390/biom9100521

2. Algul O, Ersan RH, Alagoz MA, Duran N, Burmaoglu S (2020) An efficient synthesis of novel di-heterocyclic benzazole derivatives and evaluation of their antiproliferative activities. J Biomol Struct Dyn. https://doi.org/10.1080/07391102.2020.1803966

3. Imaizumi T, Otsubo S, Komai M, Takada H, Maemoto M, Kobayashi A, Otsubo $\mathrm{N}$ (2020) The design, synthesis and evaluation of 2-aminobenzoxazole analogues as potent and orally efficacious ChemR23 inhibitors. Bioorgan Med Chem 28(17):115622. https://doi.org/10.1016/j.bmc.2020.115622

4. Easmon J, Purstinger G, Thies KS, Heinisch G, Hofmann J (2006) Synthesis, structure-activity relationships, and antitumor studies of 2-benzoxazolyl hydrazones derived from alpha- $(N)$ acyl heteroaromatics. J Med Chem 49(21):6343-6350. https:// doi.org/10.1021/jm060232u

5. Grobler JA, Dornadula G, Rice MR, Simcoe AL, Hazuda DJ, Miller MD (2007) HIV-1 reverse transcriptase plus-strand initiation exhibits preferential sensitivity to non-nucleoside reverse transcriptase inhibitors in vitro. J Biol Chem 282(11):80058010. https://doi.org/10.1074/jbc.M608274200

6. Erol M, Celik I, Ebru Uzunhisarcikli E, Kuyucuklu G (2020) Synthesis, molecular docking, and DFT studies of some new 2,5-disubstituted benzoxazoles as potential antimicrobial and cytotoxic agents. Polycyclic Aromat Compd. https://doi.org/10. 1080/10406638.2020.1802305

7. Rida SM, Ashour FA, El-Hawash SAM, ElSemary MM, Badr MH, Shalaby MA (2005) Synthesis of some novel benzoxazole derivatives as anticancer, anti-HIV-1 and antimicrobial agents. EurJ Med Chem 40(9):949-959. https://doi.org/10.1016/j. ejmech.2005.03.023

8. Raj I, Shrivastava M (2017) Antimicrobial activity of nickel(II) complex with 2-aminobenoxazole and salicylic acid. Heterocyclic Lett 7(4):1079-1083

9. Raj I, Shrivastava M (2017) Antimicrobial activity of magnese(II) complex with 2-aminobenoxazole and salicylic acid. Heterocyclic Lett 7(4):1133-1137

10. Yildiz IO, Yalcin I, Aki ES, Ucarturk N (2004) Synthesis and structure-activity relationships of new antimicrobial active multisubstituted benzazole derivatives. Eur J Med Chem 39(3):291298. https://doi.org/10.1016/j.ejmech.2003.11.014

11. Sangi DP, Meira YG, Moreira NM, Lopes TA, Leite MP, Pereira-Flores ME, Alvarenga ES (2019) Benzoxazoles as novel herbicidal agents. Pest Manag Sci 75(1):262-269. https://doi. org/10.1002/ps.5111

12. Luo B, Li D, Zhang AL, Gao JM (2018) Synthesis, antifungal activities and molecular docking studies of benzoxazole and benzothiazole derivatives. Molecules 23(10):2457. https://doi. org/10.3390/molecules23102457

13. Chin KY, El-Kayat B, Milne A, Hart A (2012) Melanoma diagnosed 27 years after a benoxaprofen-induced photosensitivity reaction. J Dermatol Case Rep 6(1):5-7. https://doi.org/10. 3315/jdcr.2012.1087

14. Dong JQ, Smith PC (2009) Glucuronidation and covalent protein binding of benoxaprofen and flunoxaprofen in sandwichcultured rat and human hepatocytes. Drug Metab Dispos 37(12):2314-2322. https://doi.org/10.1124/dmd.109.028944

15. Negri DP, Kishi Y (1987) A total synthesis of polyether antibiotic (-)-A23187 (calcimycin). Tetrahedron Lett 28(10):10631066. https://doi.org/10.1016/S0040-4039(00)95911-2 
16. Xu H, Fan LL (2011) Antifungal agents. Part 4: synthesis and antifungal activities of novel indole[1,2-c]-1,2,4-benzotriazine derivatives against phytopathogenic fungi in vitro. Eur J Med Chem 46(1):364-369. https://doi.org/10.1016/j.ejmech.2010.10. 022

17. Xu H, Fan LL (2011) Synthesis and antifungal activities of novel 5,6-dihydroindolo-[1,2-a]quinoxaline derivatives. Eur J Med Chem 46(5):1919-1925. https://doi.org/10.1016/j.ejmech.2011. 02.035

18. Fan LL, Luo BL, Luo ZF, Zhang L, Fan JD, Xue W, Tang L, Li Y (2019) Synthesis and antifungal activities of 3-substituted phthalide derivatives. Z Naturforsch B 74(11-12):811-818. https://doi. org/10.1515/znb-2019-0110

19. Fan LL, Luo ZF, Li Y, Liu XY, Fan JD, Xue W, Tang L, Li Y (2020) Synthesis and antifungal activity of imidazo[1,2-b ]pyridazine derivatives against phytopathogenic fungi. Bioorg Med Chem Lett 30(14):127139. https://doi.org/10.1016/j.bmcl.2020. 127139

20. Xu HY, Jia A, Hou EH, Liu ZY, Yang R, Yang RG, Guo Y (2020) Natural product-based fungicides discovery: design, synthesis and antifungal activities of some sarisan analogues containing 1,3,4-oxadiazole moieties. Chem Biodivers 17(2):e1900570. https://doi.org/10.1002/cbdv.201900570
21. Li Y, Luo ZF, Luo BL, Lan Q, Fan JD, Xue W, Miao J, Li Y, Tang L, Fan LL (2020) Design, synthesis and antifungal activities of 6-substituted 3-butylphthalide derivatives against phytopathogenic fungi. Chem Biodivers 17(10):e2000435. https://doi.org/10.1002/ cbdv.202000435

22. Rekowski MW, Pyriochou A, Papapetropoulos N, Stößel A, Papapetropoulos A, Giannis A (2010) Synthesis and biological evaluation of oxadiazole derivatives as inhibitors of soluble guanylyl cyclase. Bioorg Med Chem 18(3):1288-1296. https://doi. org/10.1016/j.bmc.2009.12.027

23. Fang XL, Li ZZ, Wang YH, Zhang X (2011) In vitro and in vivo antimicrobial activity of Xenorhabdus bovienii YL002 against Phytophthora capsici and Botrytis cinerea. J Appl Microbiol 111(1):145-154. https://doi.org/10.1111/j.1365-2672.2011. 05033.x

Publisher's Note Springer Nature remains neutral with regard to jurisdictional claims in published maps and institutional affiliations.

\section{Authors and Affiliations}

\section{Lingling Fan ${ }^{1} \cdot$ Zhongfu Luo $^{1} \cdot$ Changfei Yang $^{1} \cdot$ Bing Guo $^{1} \cdot$ Jing Miao ${ }^{1} \cdot$ Yang Chen $^{2} \cdot$ Lei Tang $^{1} \cdot$ Yong Li $^{1}$}

1 State Key Laboratory of Functions and Applications of Medicinal Plants and College of Pharmacy, Guizhou Provincial Engineering Technology Research Center for Chemical Drug R\&D, Guizhou Provincial Key Laboratory of Pathogenesis and Drug Research on Common Chronic Diseases, Guizhou Medical University, Guiyang 550004, People's Republic of China
2 Key Laboratory of Green Pesticide and Agricultural Bioengineering, Ministry of Education, Guizhou University, Guiyang 550025, People's Republic of China 